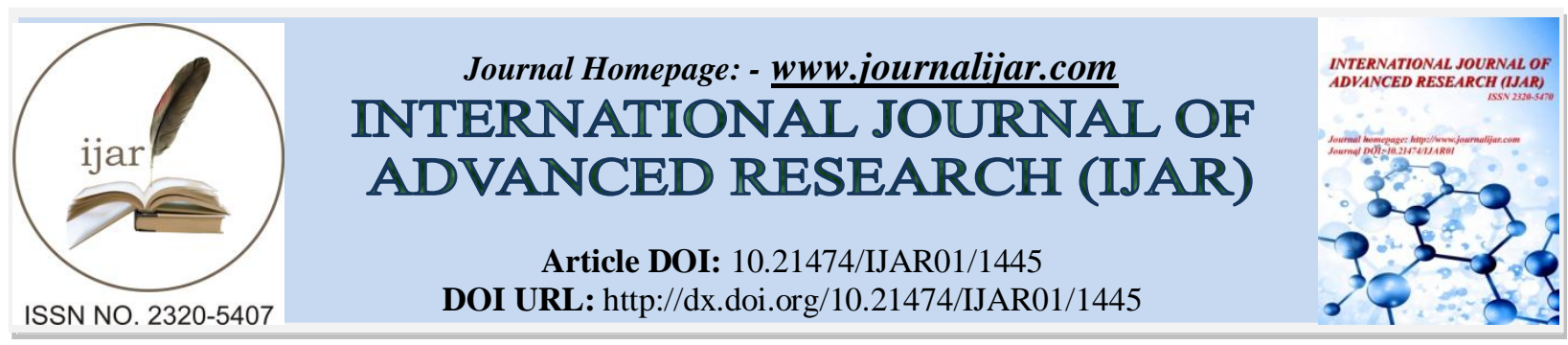

RESEARCH ARTICLE

\title{
STUDY OF SUPERFICIAL MYCOSIS AND ANTIFUNGAL SUSCEPTIBILITY TESTING IN TERTIARY HOSPITAL, BHAVNAGAR, GUJARAT.
}

Dr. Chandresh Solanki and Dr. Kairavi J. Desai

\section{Manuscript Info}

Manuscript History

Received: 15 June 2016

Final Accepted: 19 July 2016

Published: August 2016

Key words:- Superficial mycosis, Dermatophytes, Antifungal susceptibility test, Trichophyton mentagrophytes

\section{Abstract}

Present study was done clinically dignosed superficial mycosis attending the Outpatient Department of Skin and Venerology at Sir Takhtsinhji General Hospital at Bhavnagar in Gujarat .Superficial mycosis infections are very common in our country where hot and humid climate, poor hygienic conditions, low socioeconomic class play an important role in for chance to get infections The study showed a male preponderance and greater association with labourers and low socioeconomic group. Majority of patients were in 21-30 and 31-40 years of age group

Copy Right, IJAR, 2016,. All rights reserved.

\section{Introduction:-}

Skin is mechanically protective layer as well as cosmetically significant anatomical structure. The superficial cutaneous fungal infections involve its outer most covering including appendage like hair, nails. The dermatophytes are by far the most significant cutaneous fungi because their widespread .

In view of this the present study was done to find out the superficial mycosis and antifungal susceptibility testing in tertiary health care teaching Hospital, to isolate various infective fungi causing superficial mycosis and its antifungal sensitivity pattern among the patients attending Skin and Venereal diseases outpatient department, in Sir. Takhtsinhji general Hospital, Bhavnagar, Gujarat and samples processed in Mycology section of the Microbiology laboratory.

\section{Materials and methods:-}

The study group comprised of 455 patients diagnosed clinically as superficial mycosis attending the Outpatient Department of Skin and Venerology at Sir Takhtsinhji General Hospital at Bhavnagar in Gujarat. The study has been approved by the ethical committee of the institution. Newly diagnosed and untreated cases were selected for the study from November 2014 to August 2015.

\section{Direct Examination:-}

\section{Potassium Hydroxide (KOH) Preparation:-}

The samples of skin and hair were placed in few drops of 10-20\% KOH on a clean glass slide, then cover slip was placed over the preparation and the slide was gently heated(short of boiling) ${ }^{2}$ by passing over the flame 3-4 times. After 15-20 minutes, the specimen was examined first under the low power of microscope and then under the high power with low condenser to look for the presence of hyphae or arthrospores. Nail clipping was kept overnight in a sterile test tube containing $20 \% \mathrm{KOH}$ and then subjected to direct microscopy. 
The hyphal forms were differentiated from epidermal cell outlines, cotton and vegetable fibers. ${ }^{2}$

Culture:-

After direct microscopic examination, irrespective of demonstration of fungal elements, the specimen was inoculated to Following Culture medium.

\section{Sabrouad Dextrose Agar with Antibiotics (SDA):-}

It was used for primary isolation. This media contains Dextrose (40gm),Peptone(10gm),Agar(20gm), Chloramphenicol (50mg),Gentamicin (20mg),Cyclohexidine $(500 \mathrm{mg}$ ) in one litre of distilled water.

\section{Dermatophyte Testing Medium (DTM):-}

It is used for Presumptive identification of Dermatophytes. Most of the dermatophytes species produce red color due to liberation of alkaline metabolites, which changes $\mathrm{p}^{\mathrm{H}}$ and cause change in color of phenol red indicator from yellow to red.

The media contains Phyton(10gm), Dextrose(10gm), Phenol Red Solution(40ml), HCL(6ml), Actidione(500mg), Gentamicin(100mg), Chlortetracycline(100mg), Cycloheximide(500mg), Agar(20gm) in one litre of distilled water. After inoculation of material, these media were incubated at room temperature as well as in incubator at $37^{\circ} \mathrm{C}$. All cultures were examined bi-weekly for growth and incubated for at least three weeks before declaring them negative.

\section{Incubation:-}

The media is inoculated with the material and incubated at room temperature i.e., $25^{\circ} \mathrm{C} \& 30^{\circ} \mathrm{C}$ as well as at $37^{\circ} \mathrm{C}$ for minimum of fthree weeks. In majority of dermatophytes, growth and sporulation occurs in 7 to 10 days. In some it may take longer time. T. verrucosum and some strains of T. tonsurans grow better at $37^{\circ} \mathrm{C}$.

\section{Identification:-}

Identification of a dermatophyte is based on its gross colonial morphology on SDA and on its microscopic morphology. These criteria, however, may not be sufficient, especially for Trichophyton spp. That resembles each other or are variable in appearance or atypical. ${ }^{2}$

\section{Colony characteristics:-}

Gross colony characters observed on SDA include: ${ }^{2}$

- Color of the surface, i.e. of the aerial mycelium

- Color of the reverse or obverse faces of the colony production of a diffusible pigment

- Texture of the surface (glabrous or waxy, powdery, granular, suede like, velvety, downy, or fluffy)

- Topography (flat, cerebriform, crateriform)

- Growth rate. $^{2}$

\section{Microscopic morphology:-}

Microscopic morphology may be studied in teased mounts, slide cultures or pressure-sensitive tape preparations; they are examined for micro and macro conidia and their arrangement. These preparations may be mounted in lacto phenol cotton blue (LCB). ${ }^{2}$

\section{Another test for differentiation of fungi:-}

- Hair Perforation Test:

- Urease Test

- Germ tube preparation:

- Chlamydospore formation:

\section{Antifungal Susceptibility Test:-}

After getting growth, conidia were harvested in sterile saline; the conidial suspension was adjusted to $1-5 \times 10^{6}$ conidia/ml by using a $2.0 \mathrm{Mc}$ farland as comparison. Sabrouad Dextrose Agar and Dermatophyte Testing Medium plates were streaked evenly with a swab dipped into the standardized inoculum suspension. Lids were left ajar for 
3 min in a laminar flow cabinet to allow for any excess surface moisture to be absorbed into the agar before the commercially readymade drug disks were applied. Plates were inverted and incubated at $30^{\circ} \mathrm{C}$ for 4 to 7 days upto 3 weeks to allow for fungal growth. Inhibition zone diameters (IZD) were measured in millimetres. To evaluate the reproducibility of our method, a new inoculum was prepared for each replicate, all isolates were run in duplicate, and the standard deviations were determined..$^{10}$

A reference micro dilution method (M38-A2) is approved by the Clinical and Laboratory Standards Institute (CLSI) for antifungal susceptibility testing of moulds and dermatophytes. Currently, no agar-based susceptibility testing method has been standardized for testing dermatophytes. Advantages of a standardized disk diffusion-based assay for evaluating the antifungal susceptibility of dermatophytes include the ease of use, reproducibility, accuracy and low cost. ${ }^{10,11}$

Commercially available antifungal drug discs $(9 \mathrm{~mm}$ diameter) preloaded with fluconazole $(10 \mu \mathrm{g} / \mathrm{disk})$, Miconazole

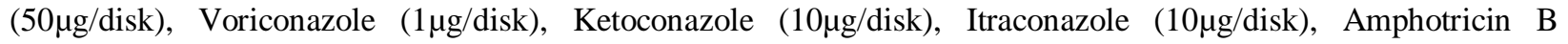

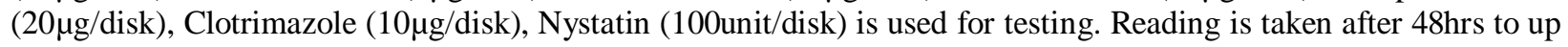
to 3 weeks on plate till the growth comes.

\section{Observation and Results:-}

This study comprises of a total 455 cases clinically suspected to be suffering from superficial mycosis coming from OPD during a period of 10 months from November 2014 to August 2015.

Table 1:- Sex wise distribution of superficial mycosis in relation to clinical types.

\begin{tabular}{|l|c|c|c|c|c|c|}
\hline Clinical Type & \multicolumn{2}{|c|}{ Male } & \multicolumn{2}{c|}{ Female } & \multicolumn{2}{c|}{ Total } \\
\hline & No. & $\%$ & No. & $\%$ & No. & $\%$ \\
\hline Tinea Corporis & 134 & $41 \%$ & 51 & $39.23 \%$ & 185 & $41 \%$ \\
\hline Tinea Cruris & 69 & $21 \%$ & 32 & $24.62 \%$ & 101 & $22 \%$ \\
\hline Tinea Capitis & 18 & $6 \%$ & 6 & $4.62 \%$ & 24 & $5 \%$ \\
\hline Tinea Pedis & 13 & $4 \%$ & 3 & $2.31 \%$ & 16 & $4 \%$ \\
\hline Tinea Unguium & 58 & $18 \%$ & 22 & $16.92 \%$ & 80 & $18 \%$ \\
\hline Tinea Barbae & 4 & $1 \%$ & 0 & $0.00 \%$ & 4 & $1 \%$ \\
\hline Tinea Mannum & 5 & $2 \%$ & 3 & $2.31 \%$ & 8 & $2 \%$ \\
\hline Tinea Faciei & 10 & $3 \%$ & 5 & $3.85 \%$ & 15 & $3 \%$ \\
\hline Mixed Tinea Infection & 14 & $4 \%$ & 8 & $6.15 \%$ & 22 & $5 \%$ \\
\hline Total & 325 & & 130 & & 455 & \\
\hline
\end{tabular}

Majority of the cases were coming from lower socioeconomic group with 286 cases $(62.86 \%)$ followed by middle socioeconomic group with 140 cases (31\%) and higher socioeconomic group with 29 cases $(6.37 \%)$.

Table 2:- Predisposing factors according to History of the patients.

\begin{tabular}{|l|c|c|}
\hline \multicolumn{1}{|c|}{ Predisposing factors } & No of Cases & Percentage \\
\hline Previous Treatment with antifungal drugs & 45 & $10 \%$ \\
\hline On Steroid Treatment & 6 & $1 \%$ \\
\hline Family History & 132 & $29 \%$ \\
\hline Sharing of Fomites & 388 & $85 \%$ \\
\hline Associated other illness-Diabetes, other skin disease & 30 & $7 \%$ \\
\hline Immunocompromised & 16 & $4 \%$ \\
\hline
\end{tabular}

Table 3:- Categorical Distribution of clinical Samples.

\begin{tabular}{|c|c|c|}
\hline Samples & No of Samples & Percentage \\
\hline Skin & 359 & $79 \%$ \\
\hline Nail & 80 & $17 \%$ \\
\hline Hair, Scalp Scraping & 16 & $4 \%$ \\
\hline Total & 455 & \\
\hline
\end{tabular}


Tinea corporis was the most common clinical condition found among 455 cases and Tinea Barbae was least common with 4 cases. Mixed infections were also noted in 22 cases.

Table 4:- Correlation of Results of KOH \& Culture.

\begin{tabular}{|l|c|c|c|}
\hline & KOH $+\mathrm{Ve}$ & KOH $-\mathrm{Ve}$ & Total \\
\hline Culture $+\mathrm{Ve}$ & $154(34 \%)$ & $25(6 \%)$ & $179(40 \%)$ \\
\hline Culture $-\mathrm{Ve}$ & $92(22 \%)$ & $174(38 \%)$ & $276(60 \%)$ \\
\hline Total & $246(56 \%)$ & $199(44 \%)$ & $455(100 \%)$ \\
\hline
\end{tabular}

Percentage of Antifungal sensitivity pattern of various clinical isolates in superficial mycosis patients.

\begin{tabular}{|c|c|c|c|c|c|c|c|c|c|}
\hline 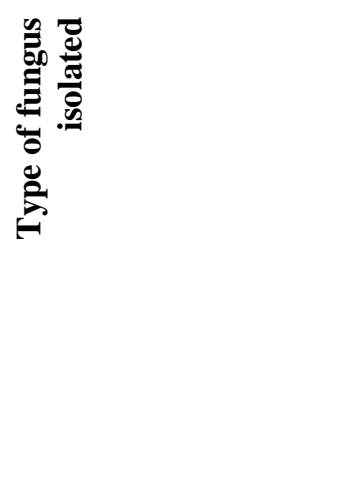 & 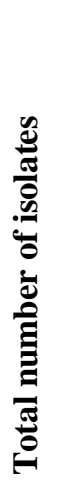 & 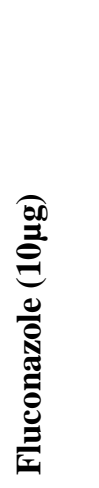 & 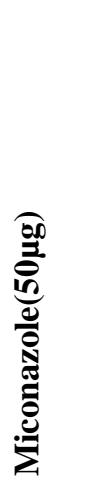 & 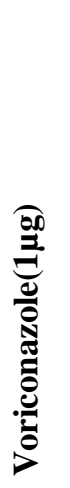 & 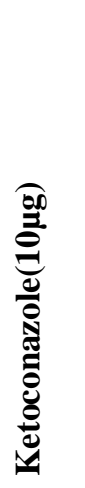 & 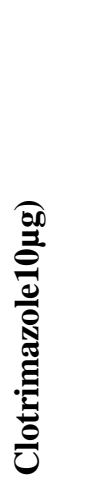 & 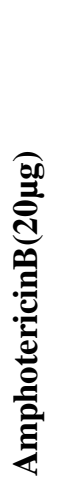 & 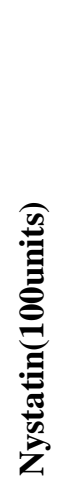 & 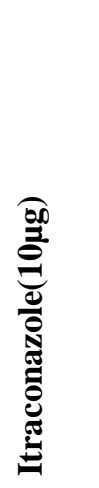 \\
\hline T.mentagrophytes & 72 & 100 & 100 & 100 & 100 & 85 & 85 & 85 & 100 \\
\hline T. rubrum & 50 & 100 & 100 & 100 & 100 & 84 & 84 & 84 & 100 \\
\hline T.tonsurans & 18 & 100 & 100 & 100 & 100 & 100 & 100 & 100 & 100 \\
\hline T.verrucosum & 17 & 100 & 100 & 100 & 100 & 100 & 100 & 100 & 100 \\
\hline M.gypseum & 1 & 100 & 100 & 100 & 100 & 100 & 100 & 100 & 100 \\
\hline M.audouinii & 1 & 100 & 100 & 100 & 100 & 100 & 100 & 100 & 100 \\
\hline M.nanum & 3 & 100 & 100 & 100 & 100 & 67 & 67 & 67 & 100 \\
\hline Fusarium & 1 & 100 & 100 & 100 & 100 & 100 & 100 & 100 & 100 \\
\hline
\end{tabular}

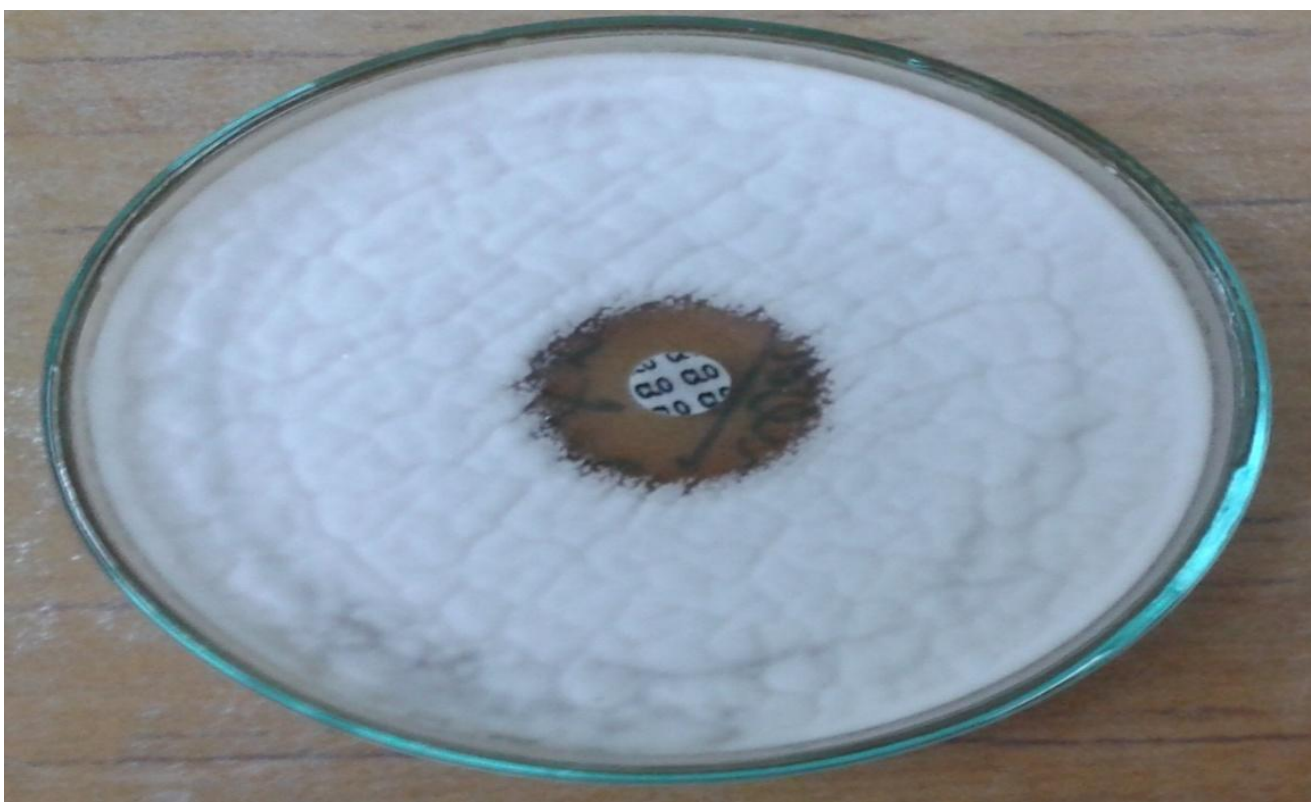

Antifungal Sensivity by Disk Diffusion Method 


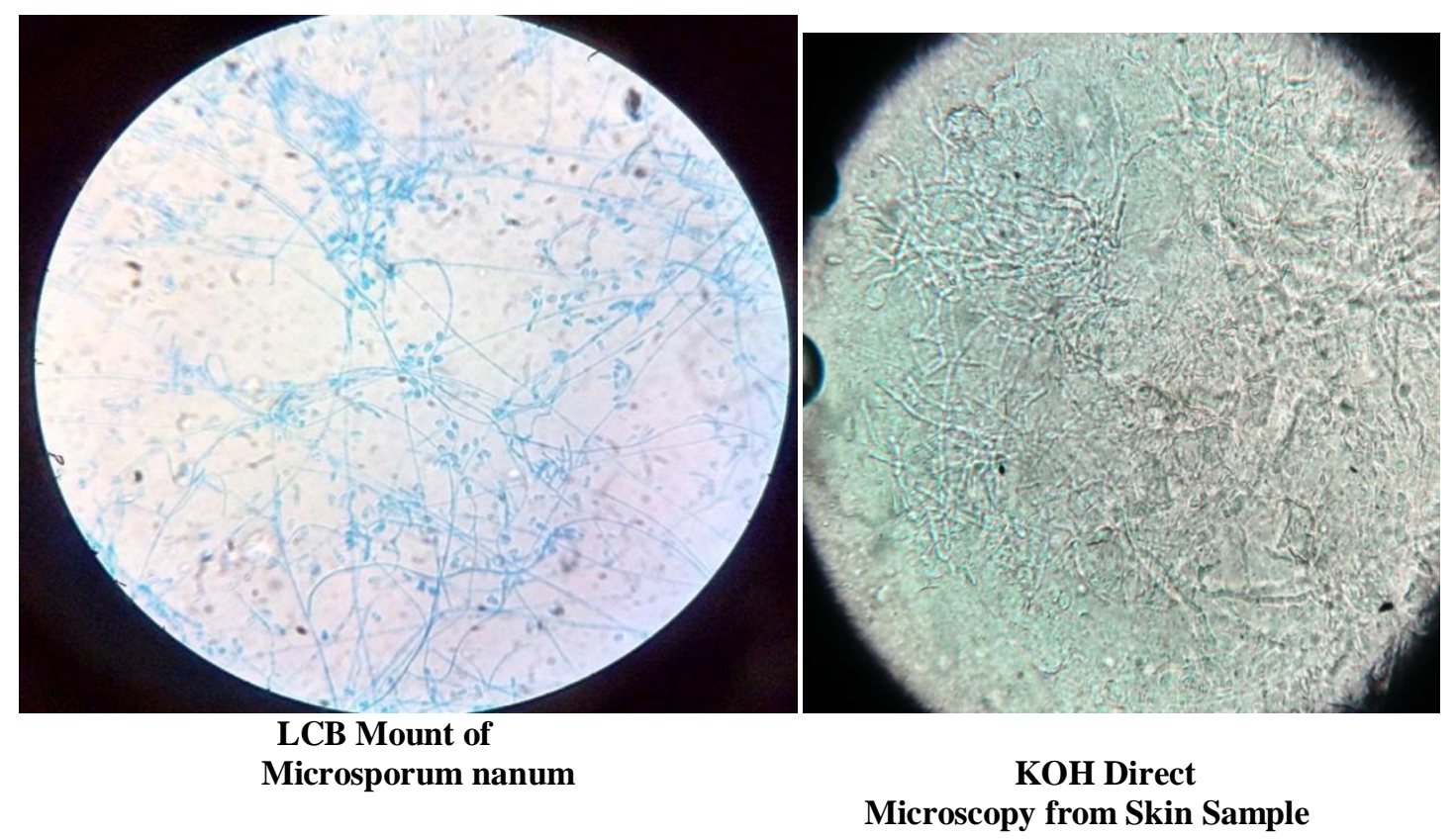

Out of 179 isolates T.mentagrophytes (11).T.rubrum (8) and M.nanum (1) resistant to three drug Clotrimazole, Nystatin and Amphotericin B antifungal drugs other five drugs are sensitive. Rests of all isolates were sensitive to all 8 antifungal drugs.

Isolation rates of superficial mycosis in processed all samples. The isolation rate of the Dermatophytes is $40 \%$ (179). Following species of Dermatophytes were isolated i.e., T.mentagrophytes, T.rubrum T.tonsurans, T.verrucosum, M.gypseum, M.audouinii, and M.nanum. Non dermatophytic dermatomycosis and onychomycosis showed presence of Candida albicans \& Fusarium. Maximum no. of dermatophytes isolated were Trichophyton mentagrophyte 72(40\%). Minimum number was M.gypseum (0.5\%), M.audouinii (0.5\%).

\section{Conclusion:-}

Superficial mycosis infections are very common in our country where hot and humid climate, poor hygienic conditions, low socioeconomic class play an important role in for chance to get infections.

There is varying difference in isolation of different species from southern and northern part of India.

The study showed a male preponderance and greater association with labourers and low socioeconomic group. Majority of patients were in 21-30 and 31-40 years of age group. Dermatophytes were most common infections found in this study.

T. mentagrophytes was the commonest isolate in Tinea corporis.

T. rubrum was the commonest isolate in Tinea corporis, Tinea cruris and Tinea capitis. Non dermatophytic fungi like Candida and Fusarium were also isolated. All dermatophytes were sensitive to 5 fluconazole, Miconazole, Voriconazole, Ketoconazole, Itraconazole antifungal drugs. Some species also resistant Clotrimazole, Nystatin and Amphotericin B drugs.

1. Jagdish Chandra. A textbook of Medical Mycology, $3^{\text {rd }}$ edition Jan 2009.

2. 2. Merz G. William, Hay J. Roderick. Topley and Wilson's Microbiology and Microbial Infections. 10th ed. Arnold Publishers; 2005.

3. J.G.Colleee, A.G.Fraser, B.P.Marmion. Mackie \& McCartney Practical Medical Microbiology,14/e.

4. A.J.E.Barlow\&Mary P. English. Fungus Disease Cutaneous Bacteriology 
5. Rechard B.Weller, Hamish.J.A.Hunter, Margarate.W.Mann, Clinical Dermatology, 5E (2015)

6. 6. E.W.Koneman, William M. Janda, Paul C. Schreckenberber, Color atlas \& textbook of Diagnostic Microbiology, $5^{\text {th }}$ Edition 1997.Lippincott, Philadelphia, New York.

7. Fisher and cook. Fundamentals of Diagnostic Mycology.W.B. Saunders Company. 1998

8. Monica cheesbrough, District laboratory practice in tropical countries, Part 2, Second Edition

9. Patrica M.Tille, Bailey \& Scott's, Diagnostic Microbiology, 13th Edition

10. E. I. Nweze, P. K. Mukherjee and M. A. Ghannoum,Agar-Based Disk Diffusion Assay for susceptibility testing of dermatophytes, J. Clin.Microbiology. Published Ahead of Print 28 July 2010.10.1128/JCM.01357-10.2010, 48(10):3750

11. CLSI. Reference Method for Broth Dilution Antifungal Susceptibility Testing of Filamentous Fungi; Approved Standard. CLSI document M38-A. CLSI, Pennsylvania, USA 2008

12. Sumana V, Singaracharya MA. Dermatophytosis in Khammam (Khammam district, Andhra Pradesh, India). Indian J Pathol-Microbiol 2004; 47(2): 287-9. 